\title{
Producción del espacio público mediante una aproximación a las ferias del agricultor: nuevos sentidos en el uso de la calle*
}

Recibido: 2 de marzo 2017 Revisado: 19 de abril 2017 Aprobado: 7 de mayo 2017

\section{Bryan Vargas Vargas}

Costarricense, sociólogo de la Universidad Nacional de Costa Rica, Licenciado en Arquitectura y Urbanismo de la Universidad Latina, estudiante de la Maestría profesional en Diseño Urbano de la facultad de arquitectura de la Universidad de Costa Rica.

Investigador social del programa Agenda Joven de Universidad Estatal a Distancia desde el 2012. Intereses de investigación, juventud, ciudad, planificación urbana y territorial. Correo electrónico: arq2vargas@gmail.com bvargas@uned.ac.cr
Resumen: Este trabajo aborda la discusión sobre la construcción social del espacio, propiamente sobre la producción del espacio público en un espaciotiempo efímero dentro de la estructura urbana como lo es una feria del agricultor. Se defiende la premisa de que el espacio público será aquel apropiado, utilizado, que convoca y que dinamiza la ciudad, sin que necesariamente sea arquitecturalizados para tales efectos. El trabajo es construido mediante observaciones, entrevistas en la feria del agricultor del cantón central de Heredia y triangulaciones entre diversos referentes teóricos.

Palabras clave: Espacio público; producción social del espacio; apropiación; encuentro

\section{Production of the Public Area Through an Approach to the Farmer's Market: New Directions in the Use of the Street}

Abstract: The current document addresses the discussion about the social construction of space, specifically about the production of public space in an ephemeral space-time within the urban structure as the farmer's market. It seeks to defend the premise that public space will be appropriate; used; that convenes and dynamizes the city without necessarily being a space defined and conceived for such purposes. The work is constructed through observations and interviews at the farmer's market in the Heredia's Central Canton, as well as triangulations with various theoretical references.

Key words: Public area; social production of urban space; appropiation; encounter 
* Un agradecimiento al arquitecto Marco Cordero por la colaboración en la aplicación de instrumentos de investigación.

1. Heredia es una ciudad de 35000 personas aproximadamente, a 10 kilómetros de San José la capital de Costa Rica. Además, forma parte de la Gran Área Metropolitana (GAM), que es una región multinuclear en donde se entrelazan las ciudades de San José, Alajuela, Cartago y Heredia en menos del $4 \%$ de territorio nacional $(196,700 \mathrm{Ha})$ y con una población aproximadamente dos millones de personas (PRODUS, 2017).

2. No en todos los casos las ferias del agricultor toman una calle o avenida urbana porque en otros lugares se ha definido un espacio permanente $y$ equipado para la realizar la actividad..
"Sofronia se compone de dos medias ciudades. Una de las medias ciudades esta fija, la otra es provisional y cuando ha terminado su tiempo de estadía, la desclavan, la desmontan y se la llevan para trasplantarla en terrenos baldíos de otra media ciudad." Ciudad de Sofronia. (Calvino, s.f.)

\section{Introducción}

La presente reflexión pretende abordar la discusión sobre el espacio como construcción social y más propiamente en la producción de un espacio público de carácter itinerante y diferenciado de lo denominado como tal, como lo pueden ser plazas, parques, jardines, bulevares, entre otros. Para este análisis, se toma como objeto el espacio-tiempo de la feria del agricultor del cantón central de Heredia ${ }^{1}$. La feria del agricultor en el contexto costarricense es un lugar de intercambio principalmente de productos agrícolas, constituido legamente en el año 2006 mediante la Ley N. ${ }^{\circ} 8533$ y es definido por el Consejo Nacional de la Producción como un "mercado minorista para uso exclusivo de pequeños y medianos productores, en forma individual u organizada, de los sectores de la producción agropecuaria, pesquera, avícola y pequeña industria y artesanía, en donde venden directamente sus productos al consumidor" (Consejo Nacional de Producción, 2016).

De esta actividad primaria de intercambio comercial entre pequeños y medianos productores de forma directa frente al consumidor, fueron observables otros movimientos de autoempleo adyacentes, que se encadenan de esta actividad principal, así como flujos de otros productos que nos muestran parte del dinamismo de este espacio-tiempo. Lo particular de esta actividad ferial en el cantón central de Heredia ${ }^{2}$ consiste en que toma un sector de la ciudad cuya función principal es cualquier otra (vacíos, aceras, calles y avenida) y se configura un nuevo sitio definido por la feria, donde incluso los elementos arquitectónicos y funcionales de la ciudad adquieren un nuevo uso.

La feria en cuestión tiene las siguientes características importantes a saber: se yuxtapone sobre la Avenida 14 al sur del casco central de la ciudad e inmediato al Hospital San Vicente de Paúl, por lo que el sector, dado la cercanía del hospital, está caracterizado por una predominancia de uso de servicios vinculados con salud. La actividad se realiza los días sábados desde tempranas horas de la mañana (5:00 a.m.), hasta aproximadamente las dos pasado meridiano (2:00 p.m.). Así, el área de la avenida donde se ubica la acción comienza a mutarse los viernes en horas de la tarde hasta el sábado en horas de la noche y cambia por completo la dinámica urbana. En adelante, se desplegarán las consideraciones de la feria del agricultor como espacio público para esto supone comprender dicho concepto. Para ello, se expone lo mencionado por Martínez Lorea en el prólogo del texto "La producción social del espacio" de Henry Lefebvre $(2013,14)$. 
El espacio debe considerarse, por tanto, un producto que se consume, que se utiliza, pero que no es como los demás objetos producidos, ya que el mismo interviene en la producción. Organiza la propiedad, el trabajo, las redes de cambio, los flujos de materias primas y energías que lo configuran y que a su vez quedan determinados por él. (Martínez en prólogo de "La producción social del espacio" 2013, 14).

En función de lo anterior, el espacio público será aquel sitio que es tomado, es utilizado, transformado y que articula relaciones sociales al crearlas y, a la vez, configurarlas. Estas son las premisas con las cuales se abordará el análisis del lugar. Se parte de las cualidades de la actividad ferial como un sitio de apropiación, encuentro, en el que además emergen formas de auto empleo y manifiesta principios deseables dentro de un espacio público. Los conceptos claves que formarán parte del desarrollo son los siguientes: producción de espacio público, legibilidad, apropiación y encuentro.

\section{Metodología}

La investigación de campo estuvo delimitada por el periodo temporal entre los meses de mayo - junio 2016 durante los días sábados y en el marco espacial sobre la avenida 14 del cantón central de Heredia, sitio donde se desarrolla la actividad ferial (Ver figura 1). Si bien la exposición ocupa la avenida indicada, otras actividades observadas y registradas desbordan esta senda, por lo que cuando se caractericen estas otras acciones adyacentes se indicará su lugar preciso. La investigación tuvo un enfoque cualitativo, es de tipo exploratorio y con alcance descriptivo. Las fuentes de la información en todo momento del trabajo de campo fueron las personas que realizaban las actividades propias dentro del espacio de la feria del agricultor: cada una en sus roles ya sean vendedores, clientes, cargadores, taxistas formales e informales y cualquier otro sujeto de interés para el objeto de estudio.

En primera instancia se realizaron observaciones exploratorias durante la actividad ferial (los sábados por la mañana) mediante una guía de observación con tres finalidades en particular: a) describir las actividades desarrolladas en general, b) caracterizar actividades de autoempleo adyacentes a la actividad comercial principal y c) identificar principios de amenidad en el espacio públi$\mathrm{co}^{3}$ que se puedan encontrar en esta ocupación efímera del espacio. Se realizaron observaciones también en periodos cortos (una hora) los días viernes por la noche para ver la instalación de los tramos que configuran la feria, la diferencia sustancial del viernes consiste en que no hay actividad comercial, únicamente los tramos ${ }^{4}$ son instalados.

3. En el análisis de este artículo se explicarán los principios de diseño a los cuales se hace referencia tomados principalmente de Jan Gehl de su clásica obra "La humanización del espacio urbano, la vida social entre los edificios" (2006).

4. Los tramos son estructuras ligeras, portables y fáciles de armar, sobre los cuales se coloca una lona colorida que funciona como cobertor de los productos a la venta, en un área aproximada a los $4 \mathrm{~m} 2(2$ $m \times 2 m)$. 
Figura 1. Mapa de zona de investigación y de nuevas actividades encontradas en la feria del agricultor Heredia. Heredia, Costa Rica.

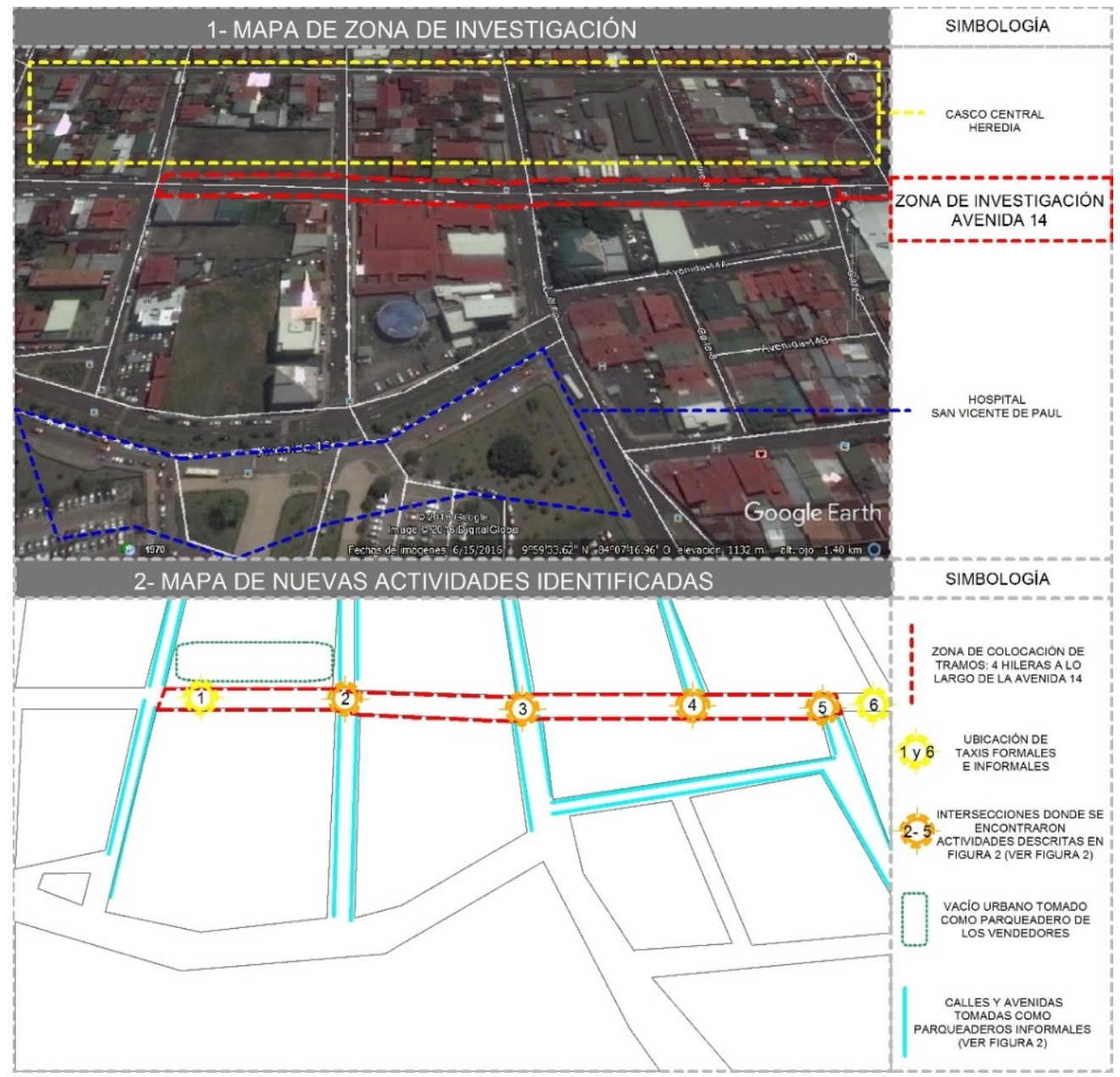

Fuente: elaboración propia con base en Google Earth, Digital Globe 2016.

Como segundo momento de recopilación de datos, se continúa con la técnica de observación con la diferencia de que se dirige el énfasis a las personas que realizaban actividades de autoempleo vistas y descritas, con las que posteriormente el investigador establece un acercamiento y se aplicaron entrevistas semiestructuradas. Esta segunda técnica contenía preguntas para la caracterización sociodemográfico, además de ítems con los cuales se obtuvo características de la actividad, a saber: a) tiempo de dedicación, b) herramientas necesarias para realizar la acción y c) otros trabajos que ejecuta la persona durante la semana. La técnica de entrevista tiene el sentido además de trascender lo que en apariencia se hace en la feria e incorporar la voz de quienes realizan las acciones. Tanto en la observación como en las entrevis- 
tas se estimó necesario recoger los datos mediante el uso de grabaciones y fotografías.

\section{Análisis}

Para iniciar en el análisis, es importante aclarar algunas situaciones históricas y coyunturales que tienen relación con la actividad estudiada. La feria del agricultor, en la ciudad de Heredia, se remonta a la década de los años ochentas con la misma intención de ofrecer a los ciudadanos una venta directa con los productores. En ese momento, ocupó los alrededores del Estadio Eladio Rosabal Cordero y en temporalidad de desarrollo los días sábados durante la mañana al igual que en la actualidad.

Más de 20 años tiene la feria de realizarse en la Avenida 14. En el año 2008, el Concejo Municipal acordó que después del primero de abril de ese mismo año las ventas no podrían instalarse más en esa senda vehicular, según los regidores de ese momento, pues la actividad afecta los accesos para realizar los trabajos de construcción del nuevo hospital San Vicente de Paúl y la dinámica de los vecinos y los comerciantes de la zona. Sumado a esto, dos años después en el 2010 la Sala Constitucional acogió un recurso de amparo que ordena trasladar la feria del agricultor porque obstaculizaba la circulación vehicular y peatonal de los usuarios del nuevo hospital (La Nación, 2008).

Desde entonces (año 2008, aproximadamente), el gobierno local trabajó en la adaptación de un espacio para la realización de la actividad ferial incluyendo algunas calidades que la actividad demanda como parqueos, servicios sanitarios, cubiertas permanentes en los tramos, rampas de acceso para personas con discapacidad, entre otras. En ese momento, se barajaron opciones de sitios y finalmente se decidió trasladarse hacia el Barrio llamado Carbonal sobre un antiguo beneficio de café en el Distrito Mercedes, a unos dos kilómetros de donde se realiza actualmente en la Avenida 14.

Continuando con los hechos según el Diario Digital CrHoy con fecha del 19 de abril del 2017 en una noticia titulada: "Traslado de la feria del agricultor de Heredia sigue frenado" indica que el traslado ha sido imposible porque el espacio habilitado para el desarrollo de la actividad ferial no tiene la capacidad de parqueos para los más 450 camiones de carga de los productores. En esta misma nota se entrevista al alcalde de la ciudad de Heredia, quien indica que el recinto ubicado en Carbonal ya está listo para ser utilizado y equipado con servicios sanitarios, parqueos para clientes, cafeterías, áreas infantiles pero que el tema del parqueo de los productores le corresponde a la Junta Cantonal, la cual de momento tiene dos opciones de terrenos ambos a más de un kilómetro del sitio de venta.

En el momento en que se destinó el sitio previsto, al parecer se omitió el volumen de los camiones de los productores y por tanto la feria del agricultor continúa hoy sobre la Avenida 14 a pesar de acuerdos municipales, recursos de amparo y la inmediatez al hospital herediano. 
Ahora, retomando el marco de la discusión que interesa en este caso: hacer énfasis por abordar la ciudad a una escala humana y no desde una perspectiva estructuralista y homogenizadora. Sobre este interés, la primera idea en el tema la retomamos del reconocimiento hecho por el profesor de la Universidad de Barcelona Manuel Delgado $(2011,15)$ sobre los aportes de Jane Jacobs en su obra "La vida y la Muerte de las grandes ciudades".

Delgado reconoce en Jacobs el surgimiento de un nuevo enfoque en la búsqueda de comprensión de la ciudad, perspectiva que estaría caracterizada principalmente por identificar "la calle" como principal escenario de encuentro, intercambio e interacción de la vida en sociedad. Como dijo la misma Jacobs $(2011,20)$ le interesa "la vida real de las ciudades", criticando en parte la planificación urbana predominante hasta ese momento, caracterizada principalmente por la lectura funcionalista y ausente de escala humana del urbanismo moderno. (Delgado en el prólogo de "La vida y la Muerte de las grandes ciudades" 2011, 15).

Otro punto reconocido en Jacobs que resulta fundamental en la caracterización de lo que llamaremos "urbanismo a nivel de la calle" es la consideración del espacio público, las aceras, los vacíos y las calles más allá de una configuración geométrica dada sino como escenario donde se reproducen las construcciones sociales; es decir, la calle como escenario donde se reproducen y son observables acciones sociales, formas de apropiación y otros fenómenos colectivos que solo se podrían dar en el marco de lo urbano, perspectiva que además hace una crítica a la arquitecturización del urbanismo, que impone instrucciones de cómo usar e interpretar los espacios urbanos. (Delgado en el prólogo de "La vida y la Muerte de las grandes ciudades", 2011, 19).

Es comparable la relación del urbanismo a nivel de calle desde los aportes de Jacobs con las posturas de autores en la ciencia social interesados en la vida cotidiana. La autora Briggitte Lamy (2006) indica sobre el urbanismo, a nivel de la calle, que es una nueva configuración intelectual que renovó el pensar lo urbano, caracterizado principalmente por los siguientes tres puntos: "1) la importancia que se le confiere al contexto; 2) la idea de que los ciudadanos disponen de competencia y conocimientos y 3) el apoderamiento de las cuestiones de espacio a partir del punto de vista de los habitantes" (Lamy, 2006, 220).

Dos aportes en este sentido significativos de mencionar son Michael H. Whyte y Hanna Arendt. El primero de ellos es conocido por su trabajo sobre la vida social de los pequeños espacios urbanos resultado de trabajos sistemáticos de observación que forman parte de esta perspectiva microsociológica o del urbanismo a nivel de la calle y la segunda autora, quien trabaja sobre el espacio público y que en términos generales lo entiende como:

Espacio de aparición donde se ponen en juego diferentes posiciones, destacando su carácter trascendente y potencial que sobrevive a la actualidad del movimiento que le 
dio existencia, y desaparece con la dispersión de los hombres, así como con la interrupción de las actividades que le dan sentido. De esta manera, lo público se produce siempre que la gente se reúne, se encuentra potencialmente allí, pero sólo potencialmente, no necesariamente ni para siempre (Arendt 1993, 222 citado por Ramírez Kuri 2007, 99).

Desde este punto de vista, otros aportes contemporáneos podrían formar de este urbanismo a nivel de calle como los aportes de Jan Gehl o de Guy Debord y la internacional situacionista, principalmente por el énfasis en el espacio público y metodologías como la deriva o del caminar/observar. El enfoque que se utiliza en la presente reflexión hace énfasis en las actividades que se desarrollan en el espacio público y las condiciones del entorno que pueden afectar positivamente o negativamente el uso de un área y el comportamiento de los usuarios en ella misma.

Con este marco de referencia y volviendo al análisis de la feria del agricultor en la ciudad de Heredia, el modelo de análisis consiste en triangulaciones de investigación; es decir, teniendo como objeto de la discusión el "espacio público", el proceder es la triangulación entre la teoría referente al tema, el trabajo de campo realizado en la feria del agricultor Heredia y las premisas presentadas en la introducción. Para entrar en el análisis, tenemos correspondencia teórica con Grégoire Chelkoff y Jean-Paul Thibaud (citados por Marrero, 2008,82 ) en cuanto "El carácter problemático del espacio público deriva del hecho de que no está predefinido de una vez por todas, sino que, al contrario, es el resultado de una construcción social; está permanentemente en proceso de producción" (Chelkoff y Thibaud citados por Marrero, 2008, 82).

La primera provocación que nos ofrece la feria del agricultor es la capacidad de agrupar y atraer personas como lo definiera Jan Gehl en su texto La humanización del espacio urbano. La vida entre los edificios (2006) generando encuentros no pactados, producto de su misma ocupación flexible del espacio. De estas atribuciones se pueden mencionar dos fenómenos observados. El primero es la diversidad de direcciones y formar de acceso de los usuarios hasta la feria del agricultor con motivaciones igual de heterogéneas, como precio, calidad de los productos, por variedad o por ocio. Esta potencialidad, de encuentro generado, nos da un rasgo que se le puede atribuir al espacio público y es que debe ser ejercido donde se tiene la autonomía de utilizar, atravesar, recorrer, comerciar y dialogar. Lo anterior tiene el alcance de articular "actividades necesarias" como el abastecerse de ciertos productos, con "actividades opcionales" como ver a la gente pasar o desayunar un bocadillo en el sitio y actividades "resultantes o sociales" que dependen de la presencia de personas en ciertos espacios (Gehl, 2006, 20). 
5. El presente trabajo tiene un sentido exploratorio y descriptivo del uso del espacio, por lo que no se propone de momento una discusión de fondo sobre autoempleo, subempleo o empleo informal.
El segundo fenómeno visto y registrado está en quienes se aproximan al dinamismo de la feria para incorporarse a un nodo de personas y autoemplearse, por ejemplo: los cuidacarros, taxistas informales, o venta de bolsas de carga, flores, rosarios, entre otros. Esto nos permite profundizar en uno de los objetos sobre los cuales se prestó mayor atención, como lo fueron las actividades de autoempleo, que emergen de este mismo reconocimiento de la feria como espacio estable en el tiempo. Seguidamente, se ofrecen algunas descripciones:

Figura 2: Caracterización de las actividades de autoempleo ${ }^{5}$ emergentes a partir de la feria del agricultor de Heredia. Mayo y junio 2016, Heredia, Costa Rica

1. Cuido de vehículos: la actividad realizada es el cuido de vehículos de los visitantes a la actividad ferial. Ello fue observable en todas las calles perpendiculares a la feria del agricultor. En algunos casos (como se ve en esta imagen), las aceras son tomadas para el parqueo de los vehículos y en los casos donde no existe acera, la calle se vuelve espacio de parqueo.

Los sujetos, que realizan esta actividad, se identifican con algún tipo de chaleco reflector que posibilite identificarlos en esta ocupación, además de algún tipo de bastón en la mano que utilizan para orientar en el estacionamiento de los vehículos. La vestimenta en general de los observados no aporta un significante de la actividad realizada.

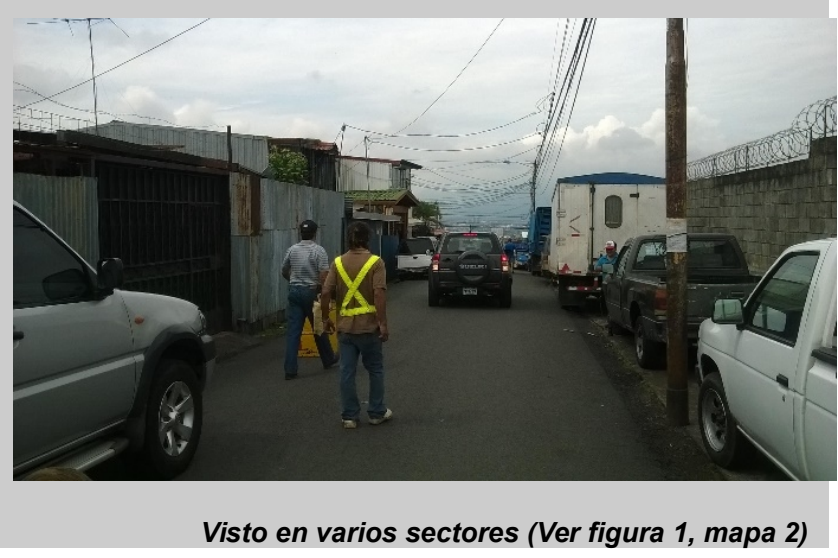

2. Venta de jugos naturales: la actividad realizada es la venta de diversas bebidas naturales (caña, zanahoria, frutas, entre otras). La misma fue observada en la calle 8 perpendicular a la feria del agricultor, yuxtapuesta a la misma se dan otras subactividades como el parqueo informal. La actividad de realiza en un camión adaptado para procesar la materia prima y para mostrarla a la venta, por lo que en este caso la herramienta (vehículo) es fundamental para que la actividad se produzca.

Los sujetos que realizan esta actividad son un hombre y una mujer, en apariencia no mayores de 30 años, quienes utilizan una camiseta con un logo que identifica la actividad.

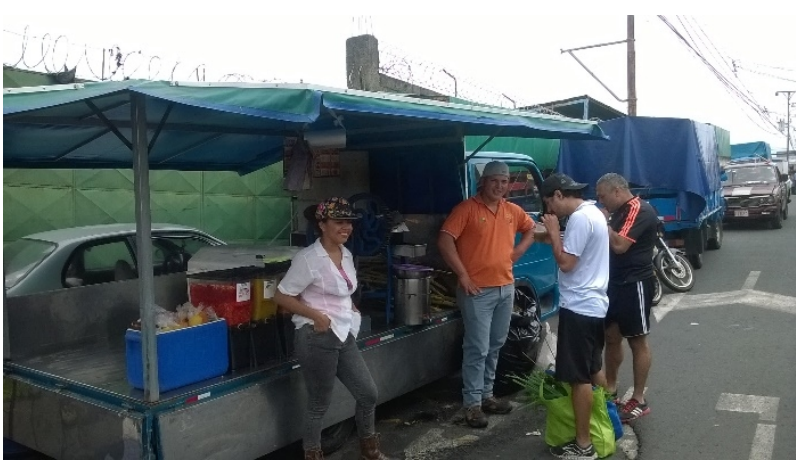

Visto en intersección 4 (Ver figura 1, mapa 2) 
3. Venta de flores: la actividad realizada es la venta de flores. Fue observada en las calles perpendiculares a la feria del agricultor, yuxtapuesta a la misma se dan otras subactividades como el parqueo informal o la venta de jugos. La actividad se realiza entre el cajón del carro y la calzada, por lo que en este caso la herramienta (vehículo) es fundamental para que la actividad se produzca.

El sujeto, que realiza esta actividad, no tiene algún elemento en su vestimenta o distintivo para mostrar su actividad.

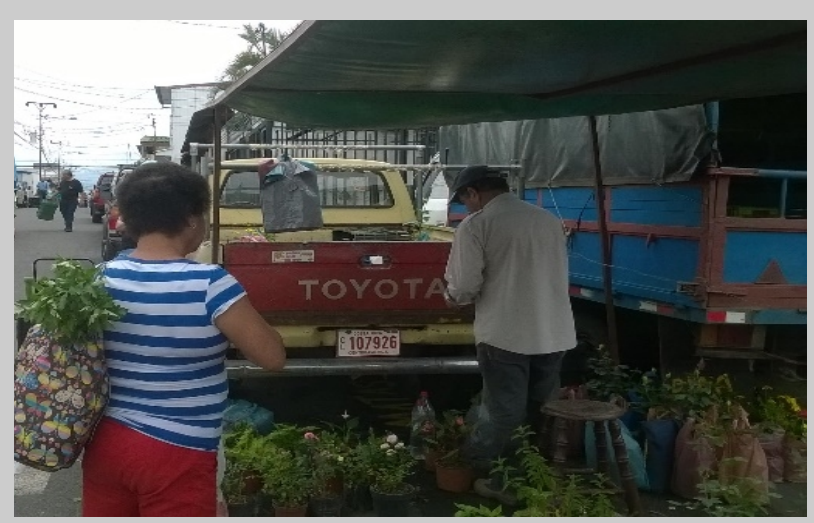

Visto en intersección 4 (Ver figura 1, mapa 2)

4. Alquiler de carritos de compra: la actividad realizada es el alquiler de carritos de compra. Se observó en la entrada de la feria, en el extremo este. Los sujetos encargados de la misma son tres personas jóvenes (dos hombres y una mujer), no mayores de 25 años, los cuales rotaban la atención de los clientes.

La herramienta indispensable para que la actividad se realice son los carritos de compras. El precio del servicio es de 700 colones (alquiler) y 1000 colones (depósito) que se le reintegran al usuario cuando devuelva el carrito de compras.

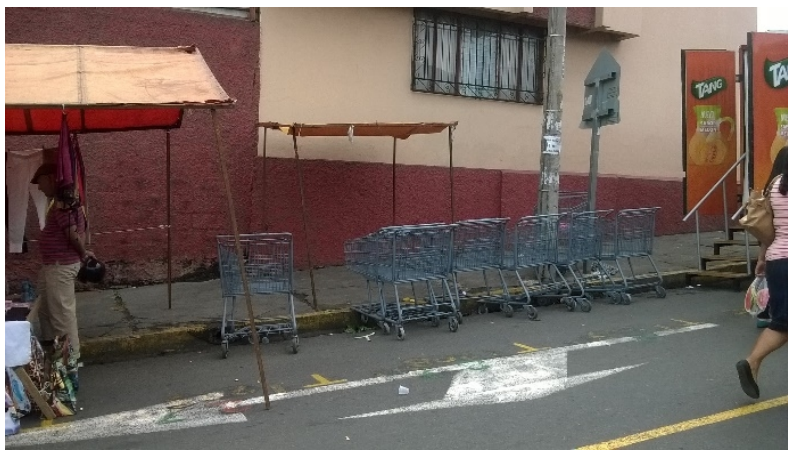

Visto en intersección 5 (Ver figura 1, mapa 2)

5. Venta de camisetas deportivas: la actividad realizada es la venta de camisetas deportivas. Esta actividad se encontró al extremo este de la feria, sobre la fachada de una vivienda al borde de la feria.

El sujeto, observado en este caso, fue una mujer de edad mayor, que no estaba de forma constante en la actividad. Para el desarrollo de esta actividad, es indispensable la ubicación y la utilización de la arquitectura como marco de muestra del producto

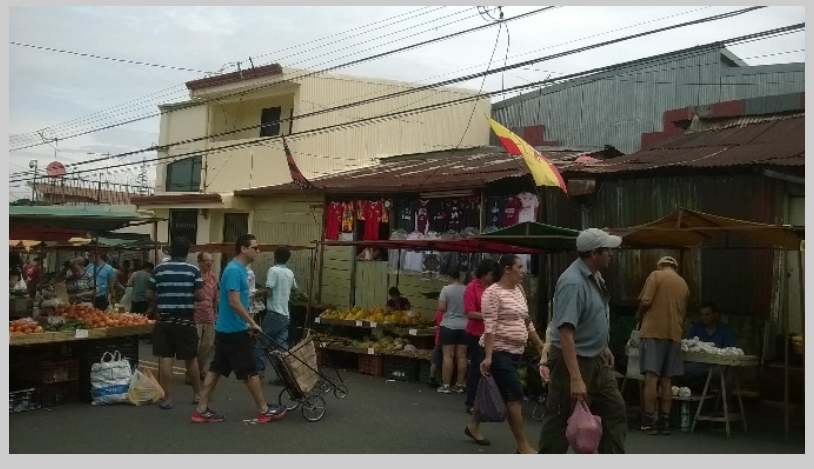
ofrecido. 
6. Venta de rosarios y bolsas de carga: la actividad realizada es la venta de rosarios y bolsas de carga. Esta actividad fue ubicada principalmente en las intersecciones entre calles y avenida 14 , pero ciertamente es una actividad que se desplaza a lo largo de la feria. La persona, en el caso de la venta de rosarios, es una mujer vestida de blanco con un tipo hábito religioso que la definía con el producto que ofrece. En el caso del vendedor de bolsas no tiene una vestimenta significante, simplemente una gorra que lo cubre de las condiciones climáticas a las que se expone.

Ambas actividades no requieren una herramienta indispensable para la realización, únicamente dependen del

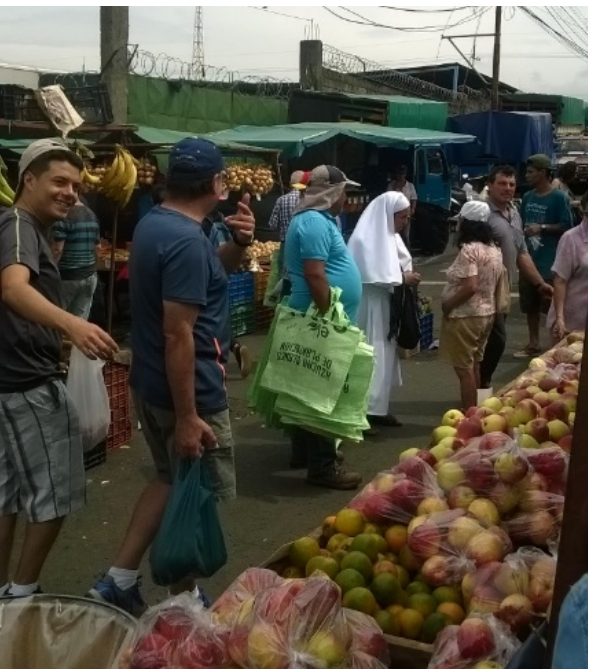
producto mismo.

7. Ventas varias: la actividad realizada es la venta de delantales, tendederos, periódicos y ajos. Si bien los productos son distintos, estos comparten la particularidad de que siempre se encontraros juntos y en una de las intersecciones (calle 12 y avenida 14). En los tres casos, los sujetos son hombres sin distintivo en sus vestimentas, que los relacione con la actividad.

La venta de delantales y tendederos se desarrolla sobre el sujeto mismo. El vendedor utiliza su cuerpo para mostrar los artículos, en los casos de la venta de periódicos y ajos los vendedores utilizan cajas plásticas para armar sus mostradores (sin tramo).

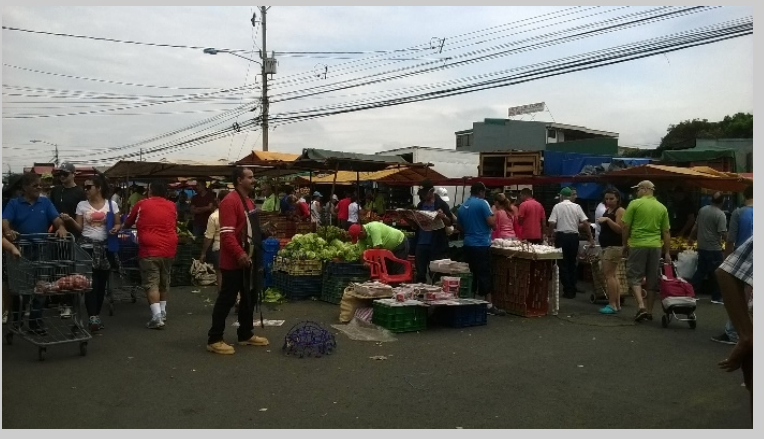

Visto en intersección 2 (Ver figura 1, mapa 2)

8. Venta de comidas: la actividad realizada es la venta de comidas. Esta actividad fue observada durante todo el tiempo de desarrollo de la feria. Era ejecutada principalmente por mujeres.

Para que la actividad se realice, es indispensable un tramo adaptado, el cual tiene su área interna cubierta para la preparación de los alimentos y un área externa, que forma una barra y con asientos perimetrales en disposición para el consumo de los alimentos. Al igual que las otras actividades ya descritas, esta se encuentra en una de las intersecciones calleavenida y paralelo de la actividad principal.

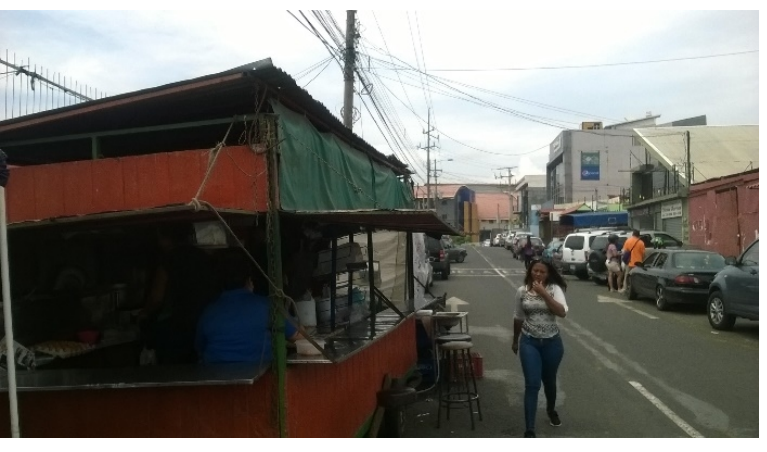

Visto en intersección 2 (Ver figura 1, mapa 2) 
9. Venta de granizados: la actividad realizada es la venta de granizados. Esta actividad se da principalmente en una de las intersecciones (calle12 y avenida 14), en el sitio se identificaron al menos tres hombres (cada uno en su carrito) de edad adulta superior a los 50 años realizando esta actividad. Para ello, es indispensable el carrito de ventas que contiene el hielo y el sirope, que es la materia prima del producto en ventas. Este carrito funciona, a su vez, como espacio de venta, por lo que es visible gente circundante.

Es posible que esta actividad se mantenga en este espacio particular y sin mayor movimiento, porque los pasos de circulación entre los tramos se vuelven muy estrechos debido a la cantidad de gente y sus correspondientes cargas, por lo que carrito de granizados representaría un obstáculo.

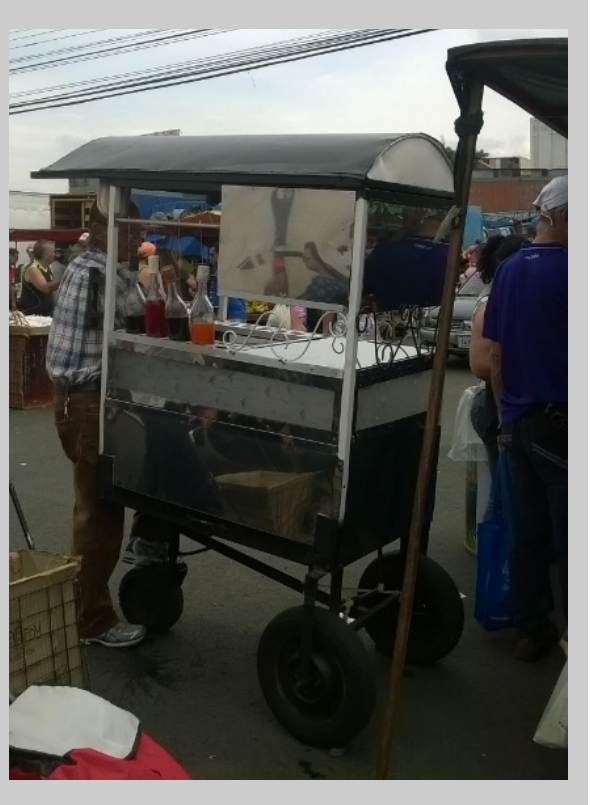

Visto en intersección 2 (Ver figura 1, mapa 2)

10. Ventas varias: la actividad realizada es la venta de productos varios por parte de personas que provienen de centros de rehabilitación (de esta forma se presentaban). Esta actividad fue observada en varias ocasiones, principalmente por hombres. Consiste en la venta de algún tipo de dulce (confites, cajetas u otros) a cambio de una moneda de cualquier valor. Las personas que realizan este canje se identifican verbalmente como miembros de alguna comunidad de rehabilitación de algún tipo de adiciones y además su vestimenta es significante.

Para la ejecución, no es necesario ninguna herramienta en particular, únicamente el producto. De todas las subactividades vistas, esta es la más se desplaza a lo largo de la feria.

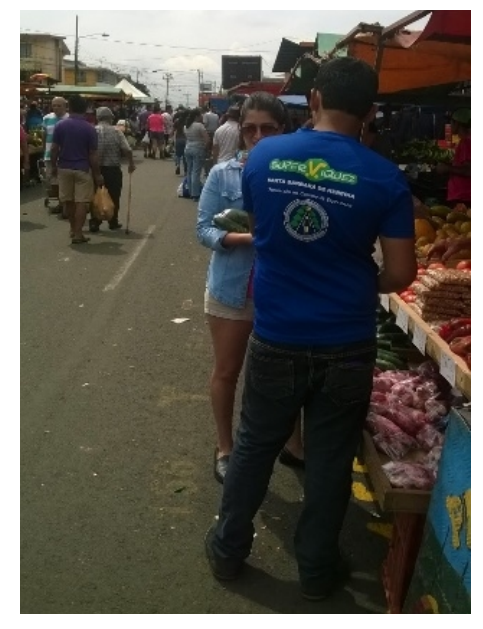

Publicidad ambulante: la actividad realizada es la publicidad de productos varios. Se observó la propaganda y las muestras de marcas comerciales (Tang, Pronol, Kolbi y Claro). Dicha actividad fue, principalmente, realizada por mujeres jóvenes e identificadas con los respectivos productos. Algunos caminaban por la feria y otras se ubicaban sobre algún tipo vehículo identificado con la marca.

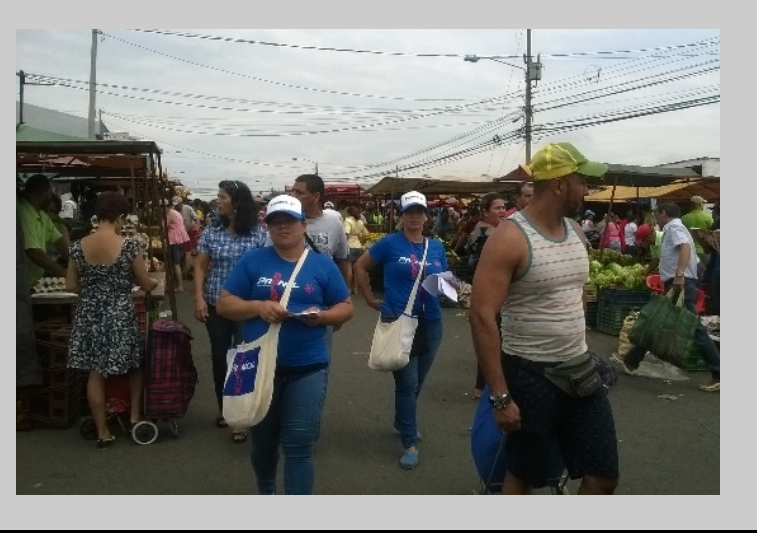

Fuente: Elaboración propia. 
Desde los primeros acercamientos a la actividad ferial fueron reconocidas las anteriores actividades ya descritas, que se mueven entre los pasillos generados por el conjunto de los tramos o en las calles conexas a la avenida 14. Este fenómeno nos habla de otro compendio de relaciones como el autoempleo y presenta una disyuntiva sobre lo que es y lo que debe ser el espacio público como apuntan Borja y Muxi $(2000,67)$ :

El espacio público es un mecanismo fundamental para la socialización de la vida urbana. La negación de la ciudad es precisamente el aislamiento, la exclusión de la vida colectiva, la segregación. Quienes más necesitan el espacio público, su calidad, accesibilidad, seguridad son generalmente los que tienen más dificultades para acceder o estar: los niños, las mujeres, los pobres, los inmigrantes recientes... En los espacios públicos se expresa la diversidad, se produce el intercambio y se aprende la tolerancia. La calidad, la multiplicación y la accesibilidad de los espacios públicos definirán en gran medida la ciudadanía (Borja y Muxi 2000, 67).

Sobre este brotar de actores que se autoemplean en la actividad ferial, es de aclarar, como se menciona en la introducción, que las ferias del agricultor son una figura constituida legalmente, pero a pesar de esta circunstancia algunas de estas personas reconocen no tener una entrada económica estable como para ocupar un puesto dentro del campo y que esta es una actividad en algunos casos ocasional, puesto que tienen otras ocupaciones los otros días de la semana o realizan esta misma actividad de forma nómada (venta de bolsas, venta de flores, venta de granizados, venta de jugos). Resultó particular de la observación que algunos vecinos aprovechan el evento para utilizar sus propios patios o entradas de las viviendas para ofrecer algún producto o cuidador vehículos frente a sus viviendas, proceder que no es generalizable por todos los vecinos o comerciantes de la zona, que en concreto ven alterada negativamente la dinámica del sur de la provincia de Heredia.

Más allá de la descripción ya expuestas, seguidamente se desarrollarán algunas de las impresiones de las personas entrevistadas ejecutando las actividades anteriores para tener una perspectiva de lo que el espacio y actividad representan.

En una de las entrevistas, con fecha del 4 de junio 2016, nuestro interlocutor fue un hombre de 73 años, quien realiza la actividad de vender bolsas de carga. Inició la entrevista al decir que a pesar de sus años de vida este trabajo lo 
mantiene con salud y de quedarse en casa seguramente estaría enfermo. Esta actividad no tiene un puesto fijo, sino que transita por toda la feria ofreciendo el producto. Sin embargo, indica que el mejor punto es en calle 6, porque por allí ingresa más gente, además en los extremos, "la gente cree que no va a comprar tanto, durante el trayecto se emocionan comprando y ya no les cabe en las bolsitas que trae, entonces deben adquirir otra conmigo", marcó.

Este mismo entrevistado, durante la semana, prepara el material que necesita para su mercancía y el fin de semana las vende en la feria de Heredia y también en la de San Rafael (aproximadamente a unos cuatro cuatro kilómetros de la feria en estudio). Trabaja en la feria desde las 5:00 a.m. a las 2:00 p.m. No tiene un puesto y no paga por estar en la feria. Indica que ya lo ha discutido con los administradores y no lo molestan por ofrecer su producto.

Este último dato es importante, porque otros de los entrevistados realizan estas actividades emergentes y sí señalan que deben estar al tanto de la Policía Municipal al no encontrarse formalizada su actividad. En ocasiones, han perdido sus productos.

En conversación con fecha del 4 de junio del 2016, la joven entrevista en la actividad de alquiler de carros de compra nos reiteró que su actividad es familiar; es decir, que otros miembros de su familia también se dedican a lo mismo, incluso en otras ferias de la provincia. Afirma que siempre están en el mismo lugar y que la idea surge en atención necesidad de las personas que ingresan al campo ferial. Señala que estar en el puesto todo el día no es lo más bonito de hacer, pero les permite ingresos para la familia y para darse algunos gustos que interesan a las personas jóvenes. Exterioriza que lo más difícil es atender las necesidades básicas como la alimentación y principalmente ir al servicio sanitario porque la feria no está dotada de este equipamiento.

En otra de las entrevistas con fecha del 4 de junio 2016, uno de los sujetos realiza la actividad de cuidacarros y nos indica que es vecino de la zona y que reside en una de las casas en el mismo lugar donde se dedica a vigilar. Lo hace desde hace más de seis meses y es una manera de colaborar en los gastos de su casa. Cercano a ser adulto mayor, aduce que es muy difícil que le den trabajo en alguna empresa por su edad y además dice que en una empresa lo hacen trabajar mucho y le pagan poco. Ante esto, afirma que con lo que recoge durante el sábado por la guardia de autos, le permite adquirir los alimentos necesarios para la semana ya que en su casa son tres personas y no tienen muchos gastos.

Su jornada inicia a las 4:00 a.m. y finaliza pasadas las 2:00 p.m. cuando cierra la feria, aunque queda alguno que otro rezagado y hay que esperar a que se marchen para recoger el dinero del trabajo realizado y teniendo siempre claro que no puede retirarse hasta que llegue el último porque de lo contrario pierde clientes y el dinero y "no se puede en estos tiempos despreciar las pocas entradas de dinero, la cosa está muy socada, para dejar pasar las oportunidades", afirmó. 
El mismo entrevistado, en su actividad de cuidar los carros, revela que sus necesidades fisiológicas las cubre allí mismo, pues está frente a su casa. Sus familiares le dan algún bocado de comida o "gallito", como él le llama, y un vaso de agua para sostenerse durante el día. Además, comentó que durante la semana, se mantiene en su casa, realiza labores de mantenimiento, encomiendas y otras atenciones que sus vecinos le solicitan, tales como ir a la farmacia del hospital o a cancelar algún recibo.

Ahora, nos referiremos a otra de las entrevistas con fecha del 4 de julio de 2016 en la actividad de ofrecer comidas de forma ambulante, principalmente se dirige hacia los vendedores de los tramos. La entrevistada vende alimentos que ella misma prepara en su casa, en uno de los distritos cercanos a unos dos kilómetros. Indica realizar esta actividad para redondearse sus ingresos económicos o entradas como ella le llama.

Refiere poseer un establecimiento donde ofrece estos mismos productos durante la semana en un otro barrio cercano a la feria. Por eso, le queda libre el sábado y sale a proporcionar sustento de puesto en puesto. Logra colocar toda su mercancía durante la mañana, pues sabe que los vendedores no tienen mayor oportunidad de trasladarse fuera de sus puestos para comprar alimentación, "así mientras venden, compran un gallito y siguen en su trabajo del día”, indicó.

La misma entrevistada dice que hay otras personas que realizan la misma actividad, ya se conocen y ofrecen almuerzos principalmente. Para ella esto no es problema, porque ya tienen clientes fijos que le han encargado almuerzos y así los trae listos. Además, señala que entre las 11:00 a.m. a las 12:00 m.d. es cuando logra mayores ganancias, pero como trabaja sola es difícil atender más gente.

Para la entrevistada, su actividad en la feria del agricultor implica trabajar desde el día anterior: prepara lo que se va a vender el día sábado, debido a que debe estar antes de las 5:00 a.m. ofreciendo desayunos. Luego, a las 9:00 a.m. con el café de media mañana y al mediodía con los almuerzos:

Es muy trabajado, se cansa una, pero es muy satisfactorio poder llevar el sustento para la familia, en la casa me ayudan un poco, pero no les gusta salir a vender, a mí no me da vergüenza. Yo les hablo a todos, les ofrezco comida muy rica, casera, a buen precio y así se me facilita realizar mis ventas, es mejor vender mucho muy bueno que poquito y caro, luego la gente no te compra más.

Este nodo de actividades y personas es un fenómeno poco frecuente en la ciudad, por lo que esta cohesión producida por la actividad ferial nos acerca a ese espacio de las premisas iniciales, así como a la idea de espacio público como ciudad y viceversa que defienden Borja y Muxi $(2000,8)$ : 
Las relaciones entre los habitantes y entre el poder y la ciudadanía se materializan, se expresan en la conformación de las calles, las plazas, los parques, los lugares de encuentro ciudadano, en los monumentos. La ciudad entendida como sistema, de redes o de conjunto de elementos -tanto si son calles y plazas como si son infraestructuras de comunicación (estaciones de trenes y autobuses), áreas comerciales, equipamientos culturales es decir espacios de uso colectivos debido a la apropiación progresiva de la gente- que permiten el paseo y el encuentro, que ordenan cada zona de la ciudad y le dan sentido, que son el ámbito físico de la expresión colectiva y de la diversidad social y cultural. Es decir que el espacio público es a un tiempo el espacio principal del urbanismo, de la cultura urbana y de la ciudadanía. Es un espacio físico, simbólico y político (Borja y Muxi 2000, 8).

La segunda provocación que hace la feria del agricultor de Heredia es que irrumpe con la función asignada en la estructura urbana; es decir, la adaptación y la apropiación de una senda de circulación vehicular por un espacio de ocupación. Como se explicaba anteriormente, la feria se realiza los días sábados en horas de la mañana, pero para que esto ocurra se disloca el espacio de tránsito por un espacio apropiado por personas, lo atrayente de este cambio es que se da el paso de un lugar nominalmente denominado como público como la avenida pero incapaz de generar vida urbana por su vocación hacia el vehículo por una actividad, que ofrece diversos servicios que convocan un número importante de personas e invita a ser travesado y se logra hacer legible la feria como propia de este tiempo-espacio.

Además, se pueden identificar usos diferentes del equipamiento urbano como lo son aceras transformadas en dormitorios de los vendedores o parqueos y fachadas de las viviendas aledañas convertidas en escaparates, entre otras situaciones ya indicadas. Es mediante esta transformación hacia su disposición ferial donde es significante un nuevo sentido del espacio urbano, la avenida 14 toma una nueva configuración, cuatro grandes líneas compuestas de tramos multicolores, dos en el centro de la calle (de espaldas entre sí) y uno a cada lado de la calzada con orientación hacia el centro, permitiendo el paso peatonal en dos sendas convirtiendo la calle en lugar causado para el encuentro. 
La tercera provocación que nos hace la actividad ferial es su legibilidad urbana. Se entiende como esa cualidad de ser reconocida determinada función en el marco urbano, que en este caso la feria misma. Contiene aristas interesantes: la primera de ellas es que, si bien la exposición es propia de los sábados durante la mañana, la continuidad durante años ha permitido a este espacio-tiempo ser registrado. Dicho reconocimiento repercute en otras dinámicas como el transporte público, ser considerado un sitio de encuentro y no solo de compra, en el que emergen actividad de autoempleo y que es visitado de formas y motivos diferentes.

La concurrencia y la permanencia en esta actividad, aunque cada ocho días, permite reconocer sus ámbitos, ocupaciones y personas, con lo cual consolidar la legibilidad como actividad en la ciudad, así como lo puede ser otro espacio público constituido para tal efecto. Habiendo presentado la feria en todas sus posibilidades, descrita desde usos socialmente organizados y encontrado personas que construyen ámbitos o microprácticas podemos decir entonces que la feria que es un logro público del espacio urbano (se practica), como indican Louis Quéré y Dietrich Brezger (citados por Marrero, 2008, 82) dicen que el espacio público es:

Por consiguiente, tratar el carácter público de un espacio urbano como un "logro" implica atraparlo en una triple dependencia en relación con las prácticas: emerge en función de los usos socialmente organizados de los espacios urbanos...; procede de las operaciones y microprácticas que se apoyan en la "competencia" de los usuarios; y finalmente, integra la implicación de estos con determinados usos y prácticas... El carácter público así aprehendido no es pues una propiedad abstracta, sino una propiedad concreta, sensible (Quéré y Brezger citados por Marrero 2008,82$)$.

\section{Conclusiones}

Señalan La Varra y Peran (1987) que en nuestras ciudades contemporáneas vagan espacios públicos errantes que emergen, mueren y renacen en otra parte. Todo esto como un rasgo de dimensiones de la vida social que se producen en la ciudad que rozan o conviven con espacios públicos tradiciones. La feria del agricultor parece ser un ejemplo de estos espacios errantes. Se caracteriza anteriormente como un espacio que irrumpe la estructura funcional urbana y provoca agrupación, atracción y apropiación y donde, además, 
el tiempo-espacio empieza a ser legible dentro de la ciudad y la dinámica urbana.

Es particular que un campo ferial efímero tenga estas cualidades, al igual que otros espacios urbanos arquitecturalizados para tales efectos, que en ocasiones permanecen sin alcanzarlas. Se considera que esta organización tiene en favor la ocupación peatonal de espacio urbano, actividades heterogéneas en relación con los productos ofrecidos, la permeabilidad de la actividad que permite ser cruzada y un sector de la ciudad que cambia sus sentidos y funciones hacia la realización de la actividad.

Por último, es importante retomar el principio de amenidad en lo urbano. Esta idea, por lo general, se asocia a la calidad del espacio físico y la incidencia de este sobre las actividades urbanas externas. En el campo ferial estudiado en su ocupación temporal, puede no satisfacer muchas necesidades climáticas, de movilidad o de equipamiento. Lo anterior es interesante porque, a pesar de esto, sí posee alcances, por ejemplo: 1. El reconocimiento y la capacidad de agrupación. 2. Generar acciones que organizan otras acciones por lo que objetaría en cierta medida la relación entre calidad física y la constancia de actividades exteriores.

Retomando el epígrafe de este artículo en la ciudad de Sofronia, la media ciudad que permanece corresponde al circo y es, a su vez, la más flexible, lúdica y en la que se está después del trabajo, mientras que la ciudad más concreta la de los ministerios, los bancos, los hospitales es la que se desplaza por otros territorios. Entonces, nos provoca pensar que lo perenne en las ciudades son las acciones y las apropiaciones y no quizá la arquitecturalización del espacio.

\section{Bibliografía}

Arendt, Hanna.1993. La Condición Humana. Barcelona: Paidos, 1993

Borja, Jordi y Zaida Muxi. 2000. «Espacio público, ciudad y ciudadanía». ESDI Barcelona. Acceso el 18 de enero de 2017. http://www.esdionline.com/repositori/public/dossiers/DIDAC_wdw7ydy1.pdf

Calvino, Italo. s.f. «Las ciudades invisibles». Elejandria. Acceso el 28 de febrero de $2017 . \quad$ Dirección

URL.http://www.elejandria.com/libros/ficha/Italo,\%20Calvino/Las

$\% 20$ ciudades $\% 20$ Invisibles $/ 134$ 
Chelkoff, Gregoire y Jean Paul Thibaud. 1992. " "L'espace public, modes sensibles. Le regard sur la ville”. "Les Annales de la Recherche Urbaine, $\mathrm{n}^{\circ}$ 57-58:7-16. Acceso el 18 de enero de 2017. http://www.persee.fr/issue/aru_0180-930x_1992_num_57_1

CNP. 2017. ¿Qué son las ferias?. Consejo Nacional de la Producción. https://www.cnp.go.cr/ferias/ (consultada el 18 de enero de 2017)

CNP. 2017. Ley N. 8533 Regulación de las ferias del agricultor. Consejo Nacional de la producción. https://www.cnp.go.cr/ferias/leyes/LEY_8533.pdf (consultada el 18 de enero de 2017)

CrHoy (2017, abril 19). «Traslado de la feria del agricultor de Heredia sigue frenado». CrHoy.com Nacionales Gobierno. https://www.crhoy.com/nacionales/traslado-de-la-feria-del-agricultor-deheredia-sigue-frenado/

Delgado, Manuel. 2011. Prólogo del texto Muerte y vida de las grandes ciudades de Jacobs Jane. Madrid: Capitán Swing, 2011.

Gehl, Jan. (2006) La Humanización del espacio. La vida entre los edificios. Barcelona: Editorial Reverté, 2006

Google Earth, Digital Globe 2016. Imagen de la ciudad de Heredia, avenida 14. Google Earth, Digital Globe 2016. https://www.google.com/earth/ (consultada el 25 de enero de 2017)

Jacobs, Jane. 2011. Muerte y vida de las grandes ciudades. Madrid: Capitán Swing, 2011

La Nación (2008, abril 3). «Feria del agricultor de Heredia continuará en avenida 14 un mes más». La Nacion.com Nacional. http://www.nacion.com/nacional/Feria-agricultor-Heredia-continuaraavenida_0_968103204.html

La Varra Giovanni y Martín Perán. 1987. «Post-it City, Ciudades Ocasionales, El último espacio público de la ciudad contemporánea». Acción Cultural 
Española y Centre de Cultura Contemporania de Barcelona. Acceso el 18 de enero de 2017. http://www.ciutatsocasionals.net/textos.htm

Lamy, Brigitte. 2006. Sociología urbana o sociología de lo urbano. Estudios Demográficos y Urbanos 21: 211-225. Acceso el 18 de enero de 2017. http://www.redalyc.org/pdf/312/31200108.pdf

Lefebvre, Henri. 2013. La producción social del espacio. Madrid: Capitán Swing Libros, S. L. 2013

Marrero, Issac. 2008. «La producción del espacio público Fundamentos teóricos y metodológicos para una etnografía de lo urbano». (con) textos.

revistad'antropologiaiinvestigaciósocialNúmero1.Maigde2008.Pàgines7 4-90.ISSN:2013-0864. Acceso el 18 de enero de 2017. http://eva.universidad.edu.uy/pluginfile.php/516078/mod_resource/cont ent/1/Etnogafia\%20de\%20lo\%20urbano.pdf

PRODUS. 2017. Observatorio Urbano. Gran Área Metropolitano. Universidad de Costa Rica. http://ougam.ucr.ac.cr/index.php/la-gam (consultada el 24 de enero de 2017)

Quere, Louis y Dietrich Brezger. 1992. «L'étrangeté mutuelle des passants. Le mode de coexistence du public urbain». Les Annales de la Recherche Urbaine, 57-58:88-100. Acceso el 18 de enero de 2017. http://www.persee.fr/issue/aru_0180-930x_1992_num_57_1

Quere, Louis y Dietrich Brezger. 2008. Citados por Marrero Issac en artículo: La producción del espacio público Fundamentos teóricos y metodológicos para una etnografía de lo urbano. (con)textos. revistad'antropologiaiinvestigaciósocialNúmero1.Maigde2008.Pàgines7 4-90.ISSN:2013-0864. Acceso el 18 de enero de 2017. http://eva.universidad.edu.uy/pluginfile.php/516078/mod_resource/cont ent/1/Etnogafia\%20de\%20lo\%20urbano.pdf

Ramírez Kuri, Patricia. 2007. La ciudad, espacio de construcción de ciudadanía. Revista Enfoques: Ciencia Política y Administración 
Pública: 85-107. Acceso el 18 de enero de 2017. http://www.redalyc.org/pdf/960/96000704.pdf 